\title{
Overt Behavior Problems and Serotonergic Function in Middle Childhood Among Male and Female Offspring of Alcoholic Fathers
}

\author{
Geoffrey R. Twitchell, Gregory L. Hanna, Edwin H. Cook, Hiram E. Fitzgerald, Karley Y. Little, and Robert A. Zucker
}

\begin{abstract}
A large body of literature indicates that the serotonergic system is involved in behavioral regulation, as evidenced by the inverse relationship between impulsive aggression and serotonergic function found in adult alcoholics and nonalcoholics. However, studles of this relationship among child and adolescent offspring of alcoholics (COAs) have not previously been done. This study examines the potentially parallel relationship between behavioral dysregulation and low serotonergic function in young COAs. The relationship is of potential interest as a phenotypic marker of biological vulnerability to aggressiveness, which itself has been hypothesized to be a risk factor for later antisocial alcoholism. The present work is part of an ongoing prospective study of the development of risk for alcohol abuse/dependence and other problematic outcomes in a sample of families subtyped by the fathers' alcoholism classification. We examined the relationship between overt behavior problems in middle childhood (mean age $=10.5 \pm 1.7$ years) and whole blood serotonin (5-HT) in a subsample of the offspring ( $N=32$ boys and 12 girls). Using a Child Behavior Checklist (CBCL) index of behavioral undercontrol, we obtained results indicating that high total behavior problem (TBP) children had lower levels of whole blood 5-HT than did low-TBP children $(0<0.01)$. These results support the hypothesis that there is an inverse relationship between whole blood serotonin levels and behavior problems in young male and female COAs. A father's alcoholism status was not significantly related to his child's 5-HT level, i.e., the child's phenotypic expression of behavioral dysregulation was more reliably connected to serotonergic function than was patemal alcoholism.

Key Words: Whole Blood Serotonin (5-HT), Behavioral Undercontrol, Children of Alcoholics, Alcoholic Subtypes, Biological Markers.
\end{abstract}

GEROTONERGIC DYSFUNCTION HAS been associ$\mathcal{N}$ ated with increased alcohol consumption, alcoholism, and--most consistently-impulsive aggression in adults recruited from clinical settings. ${ }^{1-8}$ Serotonergic status has been indexed by low levels of cerebrospinal fluid (CSF)

From the Michigan State University/University of Michigan Longitudinal Study (G.R.T., H.E.F., R.A.Z.), East Lansing, Michigan, the University of Michigan Alcohol Research Center and Department of Psychiatry (G.L.H., K.Y.L., R.A.Z.), Ann Arbor, Michigan, and the Laboratory of Developmental Neuroscience, Department of Psychiatry (E.H.C), University of Chicago, Chicago, Illinois.

Received for publication September 24, 1997; accepted April 2, 1998

This study was part of the senior author's (G.R.T.) Masters Thesis.

This research was supported by NLAAA grant RO1 AA07065, a Biomedical Research Grant from Michigan State University, and by pilot fund support from the University of Michigan Alcohol Research Center.

Reprints requests: Geoff R. Twitchell, Veterans Affairs Medical Center, West Los Angeles, Psychology Service (116B), 11301 Wilshire Boulevard, Los Angeles, CA 90073-1003. E-mail: twitche2@pilot.msu.edu.

Copyright (C) 1998 by The Research Society on Alcoholism. 5-hydroxyindoleacetic acid (5-HIAA, the major metabolite of serotonin $),{ }^{9}$ by whole blood serotonin $(5-\mathrm{HT}),{ }^{10}$ and by platelet $5-\mathrm{HT}$ uptake ${ }^{11}$ and $5-\mathrm{HT}_{2 \mathrm{~A}}$ receptor sites. ${ }^{12}$ Of particular interest are data linking serotonin deficiencies to Type II early onset male alcoholism. ${ }^{1,7,13}$ This subtype of alcoholism is distinguished by three characteristics: earlier onset of the disorder, greater alcohol-related life problems, and higher levels of violent and aggressive behavior associated with poor impulse control. It has been suggested that early onset alcoholics have a preexisting serotonin deficit that manifests in increased alcohol consumption early in life. ${ }^{1}$ Whereas Type II early onset alcoholics reportedly exhibit characteristics associated with the diagnosis of antisocial personality disorder, low CSF 5-HIAA has also been found in early onset alcoholics without antisocial personality disorder. ${ }^{13}$

Studies of children and adolescents who exhibit behavior that can be interpreted as impulsively aggressive are rare, the studies have only minimally sampled female subjects, and findings have been inconsistent. ${ }^{14-20}$ Whereas it is generally accepted that deficits in serotonergic functioning are related to alcoholism and impulsive aggression in adults, there is a lack of data examining the role this dysfunction might play in the development of children of alcoholics (COAs) who are at increased risk for both of these behavioral disorders. To our knowledge, the only study of serotonergic function in young COAs did not examine the behavioral correlates that could place these children at risk. ${ }^{21}$ In this study of abstinent adult alcoholics and their adult and younger offspring, an increase in serotonergic uptake $\left(\mathrm{V}_{\mathrm{max}}\right)$ was found in the alcoholics, compared with controls, as well as in the alcoholics' children, most of whom were in middle childhood (mean age $=11 \pm$ 1.1 years) and had never drunk alcohol, compared with ageand sex-matched control children. ${ }^{21}$ On the basis of these findings, the authors suggested that altered platelet serotonin transport might be inherited.

\section{STUDIES OF CHILDREN AND ADOLESCENTS}

Several studies have examined central (CSF 5-HIAA, neuroendocrine challenge) and peripheral (platelet 5-HT uptake, whole blood 5-HT) indices of serotonergic function in children and adolescents from clinical settings who ex- 
hibit a variety of overt behavior problems and aggressiveness. Lower CSF 5-HIAA was found in children ( $27 \mathrm{male} / 2$ female) with disruptive behavior disorders (DBDs) versus matched subjects with obsessive-compulsive disorder both at assessment (mean age $=11.3 \pm 3.6$ years) and at 2 -year follow-up (mean age $=13.8 \pm 3.9$ years). ${ }^{17,18}$ In addition, age-corrected analyses revealed negative correlations between CSF 5-HIAA and three measures of aggression. Measures of impulsivity did not differentiate between the two groups. ${ }^{17}$ Conversely, a similar study conducted in the same laboratory reported a positive correlation between CSF 5-HIAA and aggression in 29 younger male children with attention-deficit hyperactivity disorder (ADHD; mean age $=9.2 \pm 1.8$ years), who differed from the previous sample in that they exhibited much lower levels of aggression. ${ }^{15}$ Parental alcoholism status was not reported in these studies.

Neuroendocrine challenge tests have also been used as a less invasive method to assess net responsivity of the serotonergic system. No difference in prolactin response to fenfluramine challenge was observed in eight male adolescent patients with DBDs (mean age $=14.7 \pm 1.4$ years), compared with eight matched community-recruited healthy males (mean age $=15.3 \pm 1.2$ years) ${ }^{22}$ Similarly, no relationship was observed between prolactin response and two measures of aggression and hostility. In a separate group of 15 prepubertal males with one or more DBDs (mean age $=$ $10.2 \pm 2.5$ years), prolactin response to fenfluramine was not significantly correlated with two measures of hostility and antisocial behavior.

Conversely, aggressive behavior was positively correlated with prolactin response to fenfluramine in 34 younger brothers (mean age $=10.0 \pm 1.5$ years) of convicted delinquents. ${ }^{23}$ However, whereas an elevated prolactin response to fenfluramine was also found in 10 aggressive boys with ADHD (mean age $=8.6 \pm 1.3$ years of age), in comparison with 15 non-aggressive ADHD boys (mean age $=8.5 \pm 1.1$ years of age $),{ }^{24}$ this same group was unable to replicate this finding in an older sample of 13 aggressive (mean age $=9.5 \pm 1.4$ years of age) and 12 non-aggressive ADHD boys (mean age $=9.5 \pm 1.3$ years of age). ${ }^{25}$ Analyses combining the original and replication samples, divided into older and younger subgroups, found that young aggressive boys had a significantly greater prolactin response to fenfluramine than young nonaggressive boys, but no such difference existed in the older boys. The difference in prolactin response to fenfluramine challenge across the age groups was accounted for entirely by a difference across the two nonaggressive groups; younger and older aggressive children had almost identical prolactin responses to fenfluramine. The authors suggested that age-related developmental changes in 5-HT function may be important to consider when interpreting data regarding the relationship between aggression and 5-HT in children and adolescents.

Studies of 5-HT uptake measured by platelet imipramine-binding density more consistently support a relationship between serotonergic dysfunction and overt behavior problems and aggressiveness. A reduction in the density of imipramine-binding sites was found in 17 conduct-disordered (CD) plus ADHD-diagnosed children (14 boys $/ 3$ girls; mean age $=10.8 \pm 1.8$ years), compared with matched normal controls. ${ }^{20}$ In addition, a negative correlation between platelet imipramine-binding density and both externalizing behavior and aggressiveness, as measured by the CBCL, was found in the combined sample. Similarly, an inverse correlation between number of imipramine-binding sites in platelets and CBCL TBP, externalizing, hostility, and aggressiveness scores was found in a sample of 23 males (mean age $=12.6 \pm 2.2$ years) recruited from an inpatient psychiatric unit; all subjects fulfilled criteria for $C D$, and 16 also fulfilled criteria for ADHD. ${ }^{14}$ Postsynaptic indices have also been used in studying these relationships. Decreased $5-\mathrm{HT}_{2}$ receptor binding was found on platelets of 28 incarcerated male delinquent adolescents $(16.1 \pm 1.6$ years $)$ who had committed violent crimes, compared with a group of nonviolent age-matched controls. ${ }^{26}$

Because of ethical constraints, most child and adolescent studies have been restricted to peripheral indices of 5-HT function, such as whole blood 5-HT. Although whole blood 5-HT shares similar receptor, release, and transport mechanisms with serotonin neurons, ${ }^{27}$ the precise relationship of whole blood 5-HT to central serotonergic functioning is unclear. ${ }^{28}$ Unfortunately, because adult studies of aggression have focused largely on central measures of 5-HT function, findings from child and adolescent whole blood 5-HT studies cannot be compared directly to adult findings. Consequently, these studies of children and adolescents are more exploratory in nature. In addition, less consistent results have been reported in studies of whole blood 5-HT. Reduced levels of whole blood 5-HT were found in six children with both obsessive compulsive disorder (OCD) and a DBD (all male; mean age $=14.1 \pm 2.2$ years) in comparison with 12 children with only OCD (seven male, five female; mean age $=13.0 \pm 0.9$ years). ${ }^{16}$ In addition, analyses of the complete sample revealed a negative relationship between whole blood 5-HT and CBCL TBP, externalizing, and aggressive behavior scores.

Conversely, a positive correlation between clinician $\mathrm{CD}$ ratings and whole blood 5-HT was observed in a more behaviorally disturbed and older sample of 27 recently incarcerated middle-adolescent males and 17 community mental health-recruited like-aged male adolescents. ${ }^{19}$ Also, a positive correlation between whole blood 5-HT and aggression-as measured both by total offense points and the degree of violence of the offense leading to incarcerationwas found in a sample of 43 male conduct-disordered juvenile offenders (13-17 years) incarcerated for violent crimes such as murder, rape, and armed robbery. ${ }^{29} \mathrm{Al}-$ though a positive correlation between CBCL TBP scores and whole blood 5-HT was also found in 10 behaviorally disturbed boys (age 12-15 years) in residential treatment 
for unmanageable behavior, no correlation was observed in 11 younger (7- to 11-year old) similarly disturbed boys. ${ }^{30}$ Like those of Halperin et al., these findings suggest that age-related developmental changes may be important factors in examining these relationships in nonadult samples.

One study ${ }^{31}$ reported finding no difference between the whole blood 5-HT in 25 conduct-disordered children and adolescents, and that in 20 normal controls. Another study ${ }^{32}$ similarly reported no difference between the whole blood 5-HT level in 30 children with ADHD plus CD or oppositional defiant disorder (mean age $=8.2 \pm 2.4$ years) and that found in 22 children with $\mathrm{ADHD}$ only (mean age $=9.9 \pm 2.6$ years). This study ${ }^{32}$ also found no correlation between whole blood 5-HT and the CBCL Aggressive Behavior and Delinquency Subscales in 41 of these children. Relatedly, a recent review concluded that there are insufficient data to implicate a relationship between ADHD and 5-HT. ${ }^{33}$

The discrepancies in the reviewed studies may result from methodological differences, differences in the serotonergic system unique to the particular clinical populations studied, comorbidity effects, varying definitions and measures of overt behavior problems, aggression, and impulsivity, age-related developmental changes in 5-HT function, as well as variations in baseline level of aggression present in the samples. In addition, many of these studies were hampered by the use of small samples, initial level of stress (e.g., relating to incarceration or hospitalization) varied across studies, and most failed to take into account the effect of seasonal rhythms on serotonergic function. ${ }^{34}$ Overall, the CSF 5-HIAA studies of central 5-HT function and peripheral studies of platelet imipramine-binding are more consistent with the adult studies and suggest a relationship between impulsive aggression and low CSF turnover. To date, neuroendocrine challenge and whole blood 5-HT studies in children and adolescents have produced inconsistent and frequently conflicting results.

\section{Serotonergic Function and Phenotypic Expression: The Nature of the Underlying Relationship}

Aggressive disorders and level of aggression within other disorders have been shown to have varying and sometimes hard-to-interpret relationships to the serotonin system. As a first step in looking at these phenomena in COAs, we believed that it was important to examine and possibly replicate the most secure finding first. On these grounds, we chose a global index that was the best general measure of the dimension of overt behavior problems, but that also had strong positive relationships to more explicitly externalizing and aggressive behavior, namely, the CBCL TBP score.

\section{Background of the Proposed Model}

The presence of a relationship between serotonergic dysfunction and overt behavior problems in children of alco- holics is of particular interest as a phenotypic marker of biological vulnerability to early aggressiveness, which is hypothesized to be a risk factor for later antisocial alcoholism. One model supported by early data from our group proposes that greater problems in behavioral control, as evidenced by increased impulsivity in childhood, will be precursive to the development of aggressiveness, and that aggressiveness will be precursive to earlier and more severe alcoholism in later adolescence and adulthood. ${ }^{35,36}$ The strongest comorbid association with alcoholism is the coaction of antisocial personality disorder. In adults, this comorbidity has been observed in $14 \%$ of alcoholics, ${ }^{38}$ and antisocial personality disorder reportedly is also 21 times more likely to be found in alcoholics than in the general population. ${ }^{39}$ Given the strength of this connection, it has been hypothesized that differences in aggressiveness should be observable in early childhood, before alcohol involvement has begun. ${ }^{40}$ An examination of early childhood behavioral differences in 3- to 5-year-old children revealed that COAs exhibited elevated symptomatology in a number of CBCL behavioral areas, with the greatest differences occurring in the externalizing and aggression measures. ${ }^{40}$ This evidence of higher levels of externalizing behavior in early childhood parallels the evidence of later childhood and adolescent difficulty and is presumptive evidence of the potential for a continuous lifetime process.

Given the relationship between decreased serotonin neurotransmission and impulsive aggression in adult alcoholics and the greater risk for impulsivity, aggressiveness, and later alcoholism in their children, the current study was designed to examine the relationship between serotonergic function and problems in behavioral control in COAs. Because female as well as male children were available as subjects, this work would thus add to the sparse literature of children's studies by examining serotonergic function and overt behavior problems in female as well as male children. Because the adult data suggest that the role of 5-HT in behavior modulation is not limited to diagnostic categories but, rather, is dimensional in nature, the present study was designed to examine this relationship in a nonclinical community-recruited sample. In this manner, results should have greater generalizability to the establishment of risk in COAs.

It was hypothesized that greater serotonergic dysfunction as demonstrated by a lower level of whole blood 5-HT would be found in high-TBP than in low-TBP children. It was also hypothesized that paternal alcoholism subtype would be related to child serotonergic function, such that antisocial alcoholic fathers would have children who exhibited the greatest serotonergic dysfunction.

\section{MATERIALS AND METHODS}

\section{Sample}

Subjects were 44 Caucasian children between 7 and 15 years old (32 boys, 12 girls; mean age $=10.5 \pm 1.7$ years) from 33 lower to lower middle 
Table 1. Sampling Design

\begin{tabular}{llll}
\hline & \multicolumn{3}{c}{ Father's alcoholism subtype } \\
\cline { 2 - 4 } $\begin{array}{c}\text { Child's } \\
\text { classification }\end{array}$ & $\begin{array}{c}\text { Antisocial } \\
\text { alcoholic } \\
(n=11)\end{array}$ & $\begin{array}{c}\text { Nonantisocial } \\
\text { alcoholic } \\
(n=13)\end{array}$ & $\begin{array}{c}\text { Nonalcoholic } \\
\text { Control }(n=9)\end{array}$ \\
\hline Low TBP & Sons $=9$ & Sons $=10$ & Sons $=8$ \\
& Daughters $=4$ & Daughters $=3$ & Daughters $=4$ \\
High TBP & Sons $=2$ & Sons $=2$ & Sons $=1$ \\
& Daughters $=0$ & Daughters $=0$ & Daughters $=1$ \\
\hline
\end{tabular}

class families drawn from the ongoing Michigan State UniversityUniversity of Michigan Longitudinal Study. ${ }^{40-43}$ This project is following a population-based sample of children of alcoholics, both biological parents, and an ecologically comparable but nonalcoholic group of control families, at 3-year intervals, beginning when the male target children were 3 to 5 years old and the female target children were between ages 3 and 11.

Wave One involved 215 alcoholic families and 96 nonalcoholic control (NAC) families. All families were of non-Hispanic Caucasian background, which was dictated by the low base rate for non-Caucasian families in the area (less than 10\%) and the concern that inclusion would add variance that could not be evaluated. Inclusion criteria for the larger study included having a biological son between age 3 and 6 years old, living in an intact family with both biological parents. Fetal alcohol syndrome was an exclusionary criterion. ${ }^{44}$ Maternal alcoholism was neither inclusionary or exclusionary, although a subset (41\%) made a lifetime DSM-III-R alcohol abuse/dependence diagnosis.

Alcoholic families were selected in one of two ways:

1. From the population of all convicted drunk drivers in a four-county area of mid-Michigan. All men meeting the family recruitment criteria involving child's age and coupling status, who had a blood alcohol concentration $(\mathrm{BAC})$ of $0.15 \%(150 \mathrm{mg} / 100 \mathrm{ml})$ or higher when arrested or a BAC of $0.12 \%$ if a history of alcohol-related driving offenses existed, were asked for permission to release their names for contact by study staff. Seventy-nine percent agreed to have their names released, and of those, 92\% agreed to participate. All of these men met a "definite" or "probable" criterion for alcoholism by the Feighner Diagnostic Criteria, ${ }^{45}$ with $92 \%$ making a "definite" diagnosis. Later, DSM-III-R diagnoses were also established, although they were not a basis for study inclusion; $73 \%$ of the alcoholic men met either moderate or severe alcohol-dependence criteria.

2. From the same neighborhoods in which drunk-driver alcoholic fathers resided. These families provided an ecologically comparable subset of high-risk families drawn from the same social stratum as the drunk drivers, but the alcoholism was identified by way of community survey rather than by way of legal difficulty. These alcoholic fathers also met Feighner criteria (with $85 \%$ making a definite diagnosis), had children and partners who met the same inclusion criteria as the drunk-driving group, but had no drunk-driving or drug-involved record during the lifetime of the 3- to 5-year-old male target child.

In addition to alcoholic families, a control group of community families was recruited via door-to-door community survey techniques. These families were recruited from the same census tract as alcoholic families and were homogeneous with them regarding age of the male target child $( \pm 6$ months). However, neither male nor female parent met Feighner criteria for alcoholism or for other drug abuse/dependence. Ninety-three percent of families who met eligibility criteria as controls agreed to participate.

The sampling design for the present study is presented in Table 1. Families were subtyped by paternal alcoholism diagnosis and antisociality at Wave One (AAL, NAAL, or NC). Children were categorized as having high or low total behavior problems by CBCL TBP T-scores from the most recent assessment wave. Eleven of the 33 families had both a son and a daughter in the appropriate age range; in these instances, both children were included.

\section{Assessing Child Overt Behavior Problems}

The 4- to 18-year-old version of the Child Behavior Checklist ${ }^{46}$ was used to classify children as high or low on a behavioral phenotype indicator of behavioral undercontrol. The CBCL is the most commonly used questionnaire for clinical classification of child behavior problems in the United States, and the TBP score is based on a sum of all items. Maternal TBP ratings obtained at the most recent wave of data collection were used to classify children as high or low in total behavior problems. A TBP T-score of 64 or more placed the child in the clinical range; this score was used as the cutoff for a high classification. A T-score of 63 or less placed the child in the borderline clinical or normal range (classified as low total behavior problems). The TBP score was used because it is the indicator with the greatest range and because it correlates very highly with both the CBCL narrow-band Aggressive Behavior Subscale $(r=0.88, p<0.01)$ and the Externalizing Broad Band Scale $(r=0.91, p<0.01)$ in analyses of the larger longitudinal sample. Correlations of similar magnitude are also reported in the norming of the instrument. ${ }^{46}$ In addition, in the larger longitudinal study, the TBP score correlated moderately positively with ratings of impulsivity and hyperactivity on the Conners Impulsivity/Hyperactivity Scale ${ }^{47}(r=0.31, p, \leq 0.01)$. Therefore, the TBP score was conceptualized as a measure of poor behavioral control that included aspects of aggressiveness, overt externalizing behaviors and, to a lesser extent, impulsivity.

\section{Evaluating Child Alcohol Consumption}

Analysis of self report alcohol consumption (see below) revealed that $8 \%$ of the children had minimal exposure to alcohol (a sip), but none had consumed more than two drinks in their lifetime. Therefore, our sample consisted of COAs before onset of drinking.

\section{Assessing Patemal Alcoholism Subtype}

As part of the larger study, alcoholic fathers were classified at study onset as either antisocial alcoholics (AALs) or nonantisocial alcoholics (NAALs) by obtaining a measure of antisocial behavior that endured through childhood and adulthood with the Antisocial Behavior Checklist (ASBCL) ${ }^{48}$ This 46 -item self-report inventory measures the frequency of participation in various antisocial and aggressive behaviors beginning in childhood (e.g., being suspended or expelled from school for fighting, running away from home for more than a day) and continuing into adulthood (e.g., defaulting on a debt, being fired for absenteeism, resisting arrest). The measure has adequate test-retest reliability $(0.91$ over 4 weeks) and internal consistency reliability (coefficient $\alpha=0.93$ ) in populations ranging from male and female college students to male and female jail inmates. It differentiates between individuals with long histories of antisocial behavior (prisoners), individuals with more minor district court offenses, and university students. ${ }^{49}$ In addition, the ASBCL discriminates between those with antisocial personality disorder and those without such a diagnosis. ${ }^{43}$

Fathers scoring below 24 were classified as NAALs and those scoring 24 or higher were classified as AAls. This cutoff has already proved to differentiate effectively among male alcoholics in another report. ${ }^{50}$ It also provided the best combination of sensitivity $(0.85)$ and specificity $(0.83)$ in analyses comparing the instrument's classification to an independent diagnosis of antisocial personality disorder (Ellis et al., unpublished data).

\section{Medication Screening}

At the time of blood draw, the primary caretaking parent (95\% mothers) completed a child health history that assessed child's height, weight, recent illnesses, and accidents, etc., as well as the presence of any psychotropic medications taken within the past month. This medication screening allowed us to identify those children currently taking psychotropic medications and to exclude them from analyses (five children, all boys, were so excluded). In addition, each child separately and confidentially completed a brief questionnaire regarding his/her own use of cigarettes and alcohol. 
Table 2. Demographic Characteristics of High and Low Total Behavior Problem Children $(N=44 ;$ Sons $=32$, Daughters $=12)$

\begin{tabular}{|c|c|c|c|c|c|}
\hline & \multicolumn{2}{|c|}{$\begin{array}{c}\text { High TBP } \\
(n=6 ; 5 \text { sons, } 1 \text { daughter })\end{array}$} & \multicolumn{3}{|c|}{$\begin{array}{c}\text { Low TBP } \\
(n=38 ; 27 \text { sons, } 11 \text { daughters) }\end{array}$} \\
\hline & Mean & SD & Mean & $\mathrm{SD}$ & $F$ \\
\hline Child's age (yr) & 10.78 & 0.64 & 10.42 & 1.78 & 0.23 \\
\hline Father's years of education & 13.17 & 1.83 & 15.03 & 2.72 & 2.58 \\
\hline Mother's years of education & 11.83 & 1.33 & 14.18 & 2.30 & $5.88^{*}$ \\
\hline Father's degree ${ }^{a}$ & 0.33 & 0.82 & 1.08 & 1.50 & 1.41 \\
\hline Mother's degree ${ }^{a}$ & 0.17 & 0.41 & 0.74 & 0.92 & 2.20 \\
\hline Father's SES ${ }^{b}$ & 26.60 & 5.53 & 43.69 & 24.98 & 2.73 \\
\hline Mother's SES ${ }^{b}$ & 25.08 & 6.44 & 32.88 & 14.46 & 1.67 \\
\hline Family yearly income & $\$ 37,500$ & $\$ 19,365$ & $\$ 54,184$ & $\$ 24,972$ & 2.43 \\
\hline
\end{tabular}

a See text for coding formula.

b Duncan TSE12 (Stevens \& Featherman, 1981)

" $p<0.05$.

\section{Demographic Variables}

Families were characterized by demographic questionnaire measures of socioeconomic status (SES), current parental educational degree, parental years of education, family income, and child age. To code parental SES, the Revised Duncan Socioeconomic Index (Duncan TSE12) was used. ${ }^{51}$ Parental education was measured by total years of academic or vocational education (scores ranged from 10 to 20 years of education) and the highest degree achieved [scores ranged from 0 (high school diploma) to 4 (Doctoral degree)].

\section{Procedure}

Medication screening and blood sampling were performed by the first author during an in-home session, with the exception of one subject whose blood sample was drawn by a commercial laboratory. Twenty-one gauge Vacutainer brand needles were used in blood collection to ensure platelet integrity, except for the sample drawn by the commercial laboratory. That subject's whole blood 5-HT value was determined to be a significant outlier to all other data. Given the unique and anomalous data produced, this subject was dropped from analyses. Informed consent was obtained from all study participants prior to data collection and the blood draw. All subjects donated their blood samples and were paid for filling out the questionnaires.

Whole Blood 5-HT Assay. Blood was drawn from subjects into Vacutainer tubes containing ethylenediaminetetraacetic acid and was mixed by gentle inversion. The samples were immediately placed on dry ice for transport to the laboratory where they were stored frozen at $-70^{\circ} \mathrm{C}$ until the time of batch assay. Whole blood 5-HT was analyzed by high pressure liquid chromatography (HPLC) with fluorometric detection. ${ }^{52}$ 5-Hydroxytryptophan was used as an internal standard. Intraassay and interassay coefficients of variation were $2.3 \%$ and $4.0 \%$, respectively. Assays were performed blind to all demographic and diagnostic information in the Laboratory of Developmental Neuroscience at the Brain Research Institute at the University of Chicago.

\section{Statistical Analysis}

Differences between groups were tested with ANOVA. In addition, Pearson product-moment correlation coefficients were computed between child behavioral measures (TBP, Externalizing, and Aggressive Behavior Scales) and whole blood 5-HT. Raw scores were used in computing these correlations to utilize the full range of variation in the TBP score. Given that the proposed dimensional nature of the relationship suggests that the level of pathology would be expected to differ between the individuals within each dichotomous grouping, correlational analyses would allow meaningful clinical information to be obtained and would also increase the statistical power of the analyses. All probabilities reported are two-tailed.

Potential Covariates. Blood 5-HT content declines moderately in children between the ages of 10 and 12 , but after this time period there is no correlation between whole blood 5-HT and age. ${ }^{53}$ Given that our sample was within this age range, we analyzed the relationship between whole blood 5-HT and age to determine whether this association should be controlled. There was no relationship between age and whole blood 5-HT ( $r=-0.18, n=44, p=0.24$ ); neither was there a relationship between age and the independent variable of TBP $(r=0.03, p=0.82)$.

Whole blood 5-HT is not affected by ordinary changes in diet; therefore, fasting prior to venipuncture was not required. ${ }^{54,55}$ An early study found that after acute loading with tryptophan (the precursor of 5-HT), changes in blood 5-HT were transient, with a return to baseline levels within 8 hours. ${ }^{56}$ Another study, which used the same assay as in the current study, found no detectable changes in blood 5-HT levels after either oral or intravenous administration of tryptophan. ${ }^{57}$ Previous work has also shown that there is no significant diumal variation in blood 5-HT content in adults. ${ }^{58}$ However, seasonal effects on platelet 5-HT content in children and adolescents with OCD and matched normal controls have been described. ${ }^{59}$ In the present data set, blood samples were collected across three seasons (no samples were drawn during Summer). No significant relationship was found between season of blood draw and child whole blood 5-HT $(F(2,41)=1.16, p=0.32$; Winter, $n=15, \mathrm{M}=200.33$ $\mathrm{ng} / \mathrm{ml}, \mathrm{SD}=58.89 ;$ Spring, $n=15, \mathrm{M}=234.73, \mathrm{SD}=73.95 ;$ Fall, $n=14$, $\mathbf{M}=217.29 \mathrm{ng} / \mathrm{ml}, \mathrm{SD}=49.83$ ).

\section{RESULTS}

\section{Demographic Characteristics of the Sample}

Table 2 presents the sociodemographic characteristics of high- and low-TBP children. Six children (five sons, one daughter) were classified as high TBP, and 38 children (27 sons, 11 daughters) were classified as low TBP. Univariate analyses indicated that maternal years of education were higher in the low-TBP group (mean $=14.18$ years, $\mathrm{SD}=$ 2.30) than in the high-TBP group (mean $=11.83$ years, $\mathrm{SD}=1.33 ; F(1,42)=5.88, p=0.02)$.

\section{Differences in Child Whole Blood 5-HT}

To test the hypothesized relationships among child behavioral undercontrol, paternal alcoholism status, and child serotonergic function, a 2 (child TBP classification) $\times 3$ (father's alcoholism status) ANOVA with child's whole blood 5-HT as the dependent variable was conducted. For child classification, a significant main effect was present $[F(1,38)=8.28, p=0.007]$. High-TBP children exhibited significantly lower levels of whole blood 5-HT (mean = $154.00 \mathrm{ng} / \mathrm{ml}, \mathrm{SD}=36.60)$, compared with low-TBP chil- 


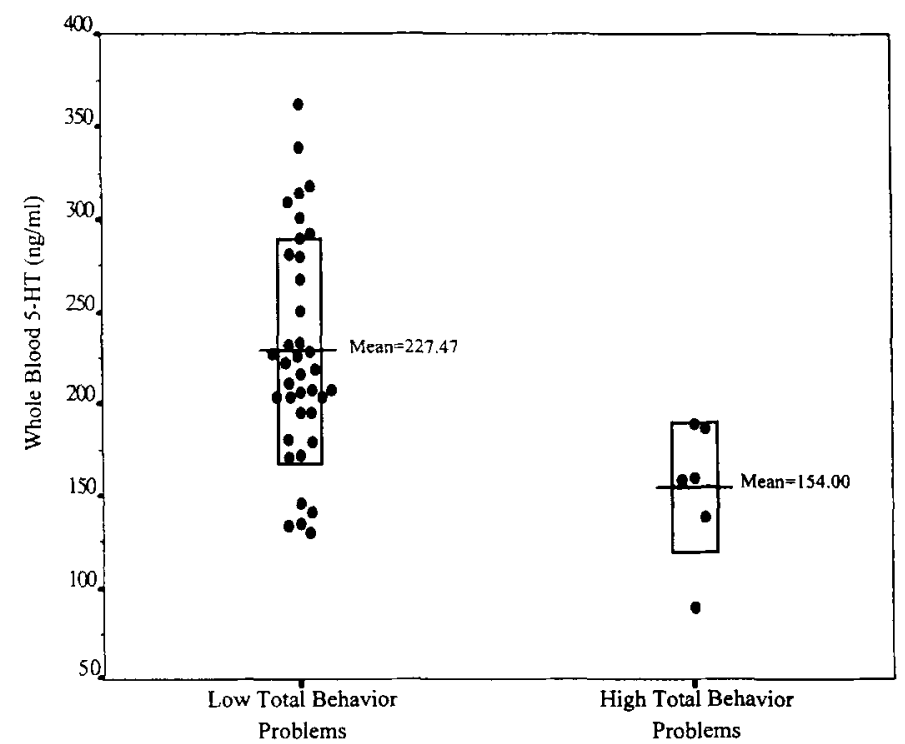

Fig. 1. Whole blood 5-HT in low total behavior problem children $(n=38$, mean $=227.47 \pm 59.64 \mathrm{ng} / \mathrm{ml})$ and high total behavior problem children $(n=6$, mean $=154.00 \pm 36.60 \mathrm{ng} / \mathrm{ml}$ ). Whole blood $5-\mathrm{HT}$ concentration for high total behavior problem children was significantly lower than for low total behavior problem children $(p<0.01)$.

dren (mean $=227.47 \mathrm{ng} / \mathrm{ml}, \mathrm{SD}=59.64)($ Fig. 1$)$. No significant main effect was observed for the father's alcoholism status $[F(2,38)=0.31, p=0.74]$ or for the interaction term $[F(2,38)=0.89, p=0.42]$. To exclude the possibility that the observed difference in whole blood 5-HT was related solely to the two extreme scores in the high behavior-problem group, a one-way ANOVA excluding these two extreme scores was conducted. Results still indicated a significant main effect for child classification $[F(1,40)=6.43, p=0.02$; high TBP, $n=4$, mean $=149.50$, $\mathrm{SD}=42.04$; low TBP, $n=38$, mean $=227.47, \mathrm{SD}=59.64]$, sustaining the original finding of group differences.

Correlational analyses on the full sample revealed a moderate relationship between child's TBP raw score and whole blood 5-HT ( $r=-0.37, N=44, p=0.01$ ) (see Fig. 2 ). As in the ANOVA analysis above, to exclude the possibility that the relationship was a result of the two extreme TBP scores, the correlation was conducted after exclusion of these scores. The analysis yielded the same significant outcome $(r=-0.34, N=42, p=0.03$ ). To provide a comparison for other studies, we performed correlational analyses between child whole blood 5-HT and both the CBCL Aggressive Behavior and Externalizing Scales $(r=$ $-0.27, p=0.08 ; r=-0.27, p=0.07$, respectively).

Diagnoses of alcoholism vary over time. ${ }^{60}$ Whereas the fathers in this sample were originally subtyped on the basis of alcoholism classifications that measured behavior exhibited at the time of their enrollment into the larger parent study (approximately 61/2 years before the collection of child whole blood 5-HT), the alcoholism diagnosis and alcoholism subtype understandably changed for some of the men over the intervening years. Hence, a more current

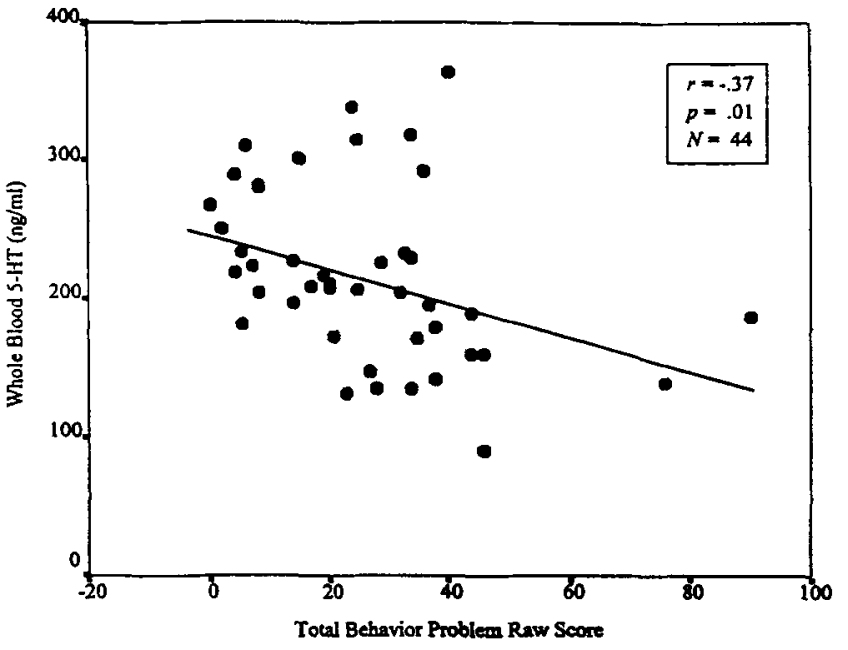

Fig. 2. Correlation between the Child Behavior Checklist Total Behavior Problem Score and whole blood 5-HT concentration.

classification of alcoholism and alcoholism subtype might more appropriately evaluate the relationship between paternal alcoholism and child serotonergic functioning. To examine this issue, we reclassified fathers according to lifetime and current alcoholism diagnoses (DSM-IV diagnostic criteria versus Feighner Diagnostic Criteria) and alcoholism subtype (a composite of Wave One and current ASBCL scores), rather than the Wave One index. In total, 14 men changed classifications from Wave One to the current Wave: one NC was reclassified a NAAL (nonantisocial alcoholic at some wave of data collection), four NAALs were reclassified as NACs (never alcoholic), one AAL was reclassified a NAC, and eight AALs were reclassified as NAALs. Of course, some of these changes in diagnosis are a function of actual changes in drinking behavior over time, whereas other reclassifications are a result of differences between Feighner and DSM diagnostic schemas and the shift from a cutoff score on the ASBCL at Wave One to the use of a composite ASBCL score in the reclassification. This reclassification produced 13 NACs, 18 NAALs, and 2 AALs (currently antisocial alcoholic). The small number of antisocial alcoholic fathers precluded our testing the relationship between current paternal subtype and current child serotonergic function, but the sample numbers did allow an examination of the relationship between father's current alcoholism (current alcoholic, $n=6$; current nonalcoholic, $n=27$ ) and current child serotonergic function. Here, also, the ANOVA reflecting the reclassification showed no significant effect of alcoholism $[F(1,42)=0.35, p=0.56]$.

An analysis of variance with gender as the independent variable and the child's whole blood 5-HT as the dependent variable failed to show a main effect for gender $[F(1,42)=$ $0.46, p=0.50$ ]. However, for informational purposes, the results were as follows: males, mean $=221.38 \mathrm{ng} / \mathrm{ml}, \mathrm{SD}=$ 68.34 ; females, mean $=207.00 \mathrm{ng} / \mathrm{ml}, \mathrm{SD}=42.32$. 


\section{DISCUSSION}

This study of COAs before onset of drinking indicates an inverse relationship between total behavior problems and whole blood 5-HT and supports the hypothesis that decreased serotonergic function is related to problems in behavioral control in young COAs who are at elevated risk for the future development of alcoholism. Although results from nonadult studies have been inconsistent, the present findings add further evidence to the hypothesis that serotonergic deficits are related to problems of behavioral control in children and adolescents. Specifically, our results parallel the findings of low whole blood 5-HT in children with $\mathrm{OCD}$ and disruptive behavior disorder, as described by Hanna et al. ${ }^{16}$ However, caution is important in drawing analogies from whole blood 5-HT to measures of CNS serotonergic function. Further investigation of the mechanism of regulation of whole blood serotonin function, such as those conducted with autistic disorder, ${ }^{61}$ would be necessary to understand the relationship between whole blood 5-HT findings and central serotonergic function in each population.

Our results did not support the hypothesized relationship between paternal antisocial alcoholism and child serotonergic function. It is possible that the observed relationship between violent alcoholism and decreased serotonergic turnover found by Virkkunen and Linnoila ${ }^{7}$ depends on the degree of violence present in the alcoholic fathers. Whereas the present study accessed a sample in which a substantial subset was antisocial (i.e., $46 \%$ of the alcoholic men), we still were not accessing the pervasive overt or reactive violence found in the Scandinavian studies. In fact, given that the hypothesized relationship in adults is between impulsive aggression and decreased serotonergic transmission, perhaps the best diagnostic correlate lies within some aspect of intermittent explosive disorder, rather than with antisocial personality disorder. For future exploration of this relationship, it may be necessary to explicitly target samples containing parents in which reactive and pervasive violence is present.

Serotonergic function as measured by CSF 5-HIAA has proved to be highly heritable and to exhibit intraindividual stability in nonhuman primates, ${ }^{62}$ as well as in humans. ${ }^{63}$ However, data suggest that this dysfunction, when inherited, can be exacerbated or dampened by experience. Nonhuman primate studies have found that the peer rearing of infants, an analog of early parental neglect, leads to lower CSF 5-HIAA in infants, as early in life as 14 days. Furthermore, this deficit continues into adulthood. ${ }^{64}$ Peer-reared monkeys were found to drink more alcohol than motherreared monkeys and to exhibit less social dominance. Both low CSF 5-HIAA and social competence were correlated with excessive alcohol consumption. These authors concluded that peer-reared monkeys exhibited several behaviors that made them good animal models of Cloninger's Type II alcoholism. ${ }^{65}$ When low serotonergic functioning monkeys from both peer-reared and mother-reared environments were followed into adulthood, the peer-reared monkeys exhibited more socially inept behavior and were more often thrown out of their social groups for exhibiting excessive aggression and deviant social behavior. ${ }^{64}$ These authors concluded that the experience of peer-rearing aggravated the negative consequences associated with low serotonergic function. Similarly, this study found that the immediate environment could also influence behavior above and beyond serotonin level. The observable difference in alcohol intake between the two groups disappeared when the mother-reared animals were faced with the stressful situation of separation from their social group. At that point, the mother-reared monkeys drank similar amounts of alcohol.

One study of humans found that the socioenvironmental factors of harsh parenting, parental alcoholism, and parental incarceration were associated with low serotonergic function as measured by reduced $5-\mathrm{HT}_{2 \mathrm{~A}}$ receptor density on platelets in 34 younger brothers of convicted delinquents (mean age $=8.3 \pm 1.4$ years) ${ }^{34}$ This group also found that adverse rearing was positively correlated with prolactin response to fenfluramine challenge, independent of the relationship between prolactin response to fenfluramine and aggression, in a separate study of 34 younger brothers of convicted delinquents (mean age $=10.0 \pm 1.5$ years) ${ }^{23}$ These authors warn that parental characteristics and early familial experiences may confound the relationships between a child's behavior and serotonergic profile. Consequently, early behavioral and environmental intervention may positively modify existing serotonergic functioning.

Whereas the present study benefited from the direct assessment of parents, the findings are limited by the lack of available categorical diagnoses for children. Another study limitation is the use of only one indicator, whole blood 5-HT, to characterize central serotonergic function. Although our results failed to support a relationship between age and whole blood 5-HT in the combined sample, the reader should keep in mind that the often-reported negative relationship cited in the literature was present in the sample of boys $(r=-0.39, n=32, p=0.03)$. Similarly, although the present data failed to show an effect for seasonality, our sampling was inadequate to assess seasonal variation fully.

The present findings are consistent with adult data and with most existing child and adolescent data, and they indicate that childhood serotonergic dysfunction is related to overt behavior problems through a hypothesized primary deficit in behavioral inhibition. The fact that these findings were made in a medication-free, community-recruited sample, and in an age range in which drinking of alcohol had not yet begun, lends further strength to their potential generalizability. The utility of this relationship as a potential marker for the later development of antisocial alcoholism or other behavioral difficulties will need to be assessed by continued study of this population through time. In the 
future, it would be worthwhile to clarify age and seasonal effects on whole blood 5-HT, to describe the relationship between whole blood 5-HT and categorical diagnoses in the children, to describe the parent-child correlations in whole blood 5-HT, and to assess the ratios of plasma tryptophan to large neutral amino acids. Future work with this sample will also examine the impact of psychosocial and socioenvironmental variables on child serotonergic function in an effort to gain a more comprehensive understanding of the observed relationship between the behavioral phenotype and the neurobiological substrate.

\section{REFERENCES}

1. Buydens-Branchey L, Branchey MH, Noumair D, Lieber CS: Age of alcoholism onset: II. Relationship to susceptability to serotonin precursor availability. Arch Gen Psychiatry 46:231-236, 1989

2. Coccaro EF: Central serotonin and impulsive aggression. $\mathrm{Br} \mathrm{J}$ Psychiatry $155: 52-62,1989$

3. McBride WJ, Murphy JM, Lumeng L, Li TK: Serotonin and ethanol preference. Recent Dev Alcohol 7:187-209, 1989

4. Naranjo CA, Sellers EM, Larwin MO: Modulation of ETOH intake by 5-HT uptake inhibitor. J Clin Psychiatry 47:16-22, 1986

5. Naranjo CA, Sellers EM, Sullivan JT, et al: The serotonin uptake inhibitor citalopram attenuates ethanol intake. Clin Pharmacol Ther 41: $266-274,1987$

6. Tollefson GD: Serotonin and alcohol: Interrelationships. Psychopathology 22:37-48, 1989

7. Virkkunen M, Linnoila M: Serotonin in early onset, male alcoholics with violent behavior. Ann Med 22:327-331, 1990

8. Virkkunen M, Nuutila A, Goodwin F, Linnoila M: Cerebrospinal fluid monoamine metabolites in male arsonists. Arch Gen Psychiatry 44:241-247, 1987

9. Ballenger JC, Goodwin FK, Major LF, Brown GL: Alcohol and central serotonin metabolism in man. Arch Gen Psychiatry 36:224-227, 1979

10. Banki CM: 5-Hydroxytryptamine content of the whole blood in psychiatric illness and alcoholism. Acta Psychiatr Scand 57:232-238, 1978

11. Rausch JL, Monteiro MG, Schuckit MA: Platelet serotonin uptake in men with family histories of alcoholism. Neuropsychopharmacology $4: 83-86,1991$

12. Coccaro EF, Kavoussi RJ, Sheline YI, Berman ME, Csernansky JG: Impulsive aggression in personality disorder correlates with platelet 5- $\mathrm{HT}_{2 \mathrm{~A}}$ receptor binding. Neuropsychopharmacology 16:211-216, 1997

13. Fils-Aime M, Eckardt M, George D, et al: Early-onset alcoholics have lower CSF 5-HIAA than late-onset alcoholics. Arch Gen Psychiatry 53:211-216, 1996

14. Birmaher B, Stanley M, Greenhill L, et al: Platelet imipramine binding in children and adolescents with impulsive behavior. J Am Acad Child Adolesc Psychiatry 29:914-918, 1990

15. Castellanos FX, Elia J, Kruesi MJP, et al: Cerebrospinal fluid monoamine metabolites in boys with attention-deficit hyperactivity disorder. Psychiatry Res 52:305-316, 1994

16. Hanna G, Yuwiler A, Coates JK: Whole blood serotonin and disruptive behaviors in juvenile obsessive-compulsive disorder. J Am Acad Child Adolesc Psychiatry 34:28-35, 1995

17. Kruesi MJP, Rapoport JL, Hamburger S, et al: Cerebrospinal fluid monoamine metabolites, aggression, and impulsivity in disruptive behavior disorders of children and adolescents. Arch Gen Psychiatry 47:419426,1990

18. Kruesi MJP, Hibbs ED, Zahn TP, et al: A 2-year prospective follow-up study of children and adolescents with disruptive behavior disorders: Prediction by cerebrospinal fluid 5-hydroxyindoleacetic acid, homovanillic acid, and autonomic measures. Arch Gen Psychiatry 49:429_ 435,1992
19. Pliszka SR, Rogeness GA, Renner P, Sherman J, Broussard R: Plasma neurochemistry in juvenile offenders. J Am Acad Child Adolesc Psychiatry 27:588-594, 1988

20. Stoff DM, Pollock L, Vitiello B, Behar D, Bridger WH: Reduction of $\left({ }^{3} \mathrm{H}\right)$-imipramine binding sites on platelets of conduct-disordered children. Neuropsychopharmacology 1:55-62, 1987

21. Ernouf D, CompagnonP, Lothion P, et al: Platelets $3 \mathrm{H} 5-\mathrm{HT}$ uptake in descendants from alcoholic patients: A potential risk factor for alcohol dependence. Life Sci 52:989-995, 1993

22. Stoff DM, Pasatiempo AP, Yeung J, et al: Neuroendocrine responses to challenge with dl-fenfluramine and aggression in disruptive behavior disorders of children and adolescents. Psychiatry Res 43:263276, 1992

23. Pine DS, Coplan JD, Wasserman GA, et al: Neuroendocrine response to fenfluramine challenge in boys: Associations with aggressive behavior and adverse rearing. Arch Gen Psychiatry 54:839-846, 1997

24. Halperin JM, Sharma V, Siever LJ, et al: Serotonergic function in aggressive and nonaggressive boys with attention deficit hyperactivity disorder. Am J Psychiatry 151:243-248, 1994

25. Halperin JM, Newcorn JH, Schwartz ST, et al: Age-related changes in the association between serotonergic function and aggression in boys with ADHD. Biol Psychiatry 41:682-689, 1997

26. Blumensohn R, Ratzoni G, Weizman A, et al: Reduction in serotonin $5 \mathrm{HT}_{2}$ receptor binding on platelets of delinquent adolescents. Psychopharmacology 118:354-356, 1994

27. Pletscher A: The 5-hydroxytryptamine system of blood platelets: Physiology and pathophysiology. Int J Cardiol 14:177-188, 1987

28. Stoff DM, Vitiello B: Role of serotonin in aggression of children and adolescents: Biochemical and pharmacological studies, in Stoff DM and Cairns RB (eds): Aggression and Violence: Genetic, Neurobiological, and Biosocial Perspectives. Mahwah, NJ, Erlbaum Asociates, 1996, pp 101-123

29. Unis AS, Cook EH, Vincent JG, et al: Platelet serotonin measures in adolescents with conduct disorder. Biol Psychiatry 42:553-559, 1997

30. Gabel S, Stadler J, Bjorn J, Shindledecker R, Bowden C: Dopamine-beta-hydroxylase in behaviorally disturbed youth: Relationships between teacher and parent ratings. Biol Psychiatry 34:434-442, 1993

31. Rogeness GA, Hernandez JM, Macedo CA, Mitchell EL: Biochemical differences in children with conduct disorder socialized and undersocialized. Am J Psychiatry 139:307-311, 1982

32. Cook EH, Stein MA, Ellison T, Unis AS, Leventhal BL: Attention deficit hyperactivity disorder and whole blood serotonin levels: Effects of comorbidity. Psychiatry Res 57:13-20, 1995

33. Zubieta JK, Alessi NE: Is there a role of serotonin in the disruptive behavior disorders? A literature review. J Child Adolesc Psychopharmacol 3:11-35, 1993

34. Pine DS, Wasserman GA, Coplan J, et al: Platelet serotonin 2A $\left(5-\mathrm{HT}_{2 \mathrm{~A}}\right)$ receptor characteristics and parenting factors for boys at risk for delinquency: Preliminary report. Am J Psychiatry 153:538-544, 1996

35. Zucker RA, Fitzgerald HE: Early developmental factors and risks for alcohol problems. Alcohol Health Res World 15:18-22, 1991

36. Jansen RE, Fitzgerald HE, Ham HP, Zucker RA: Pathways into risk: Temperament and behavior problems in three- to five-year-old sons of alcoholics. Alcoholism: Clin Exp Res 19:501-509, 1995

37. Deleted in proof

38. Regier DA, Farmer ME, Raw DS, et al: Comorbidity of mental disorders with alcohol and other drug abuse. JAMA 264:2511-2518, 1990

39. Helzer JE, Burnam A, McEvoy LT: Alcohol abuse and dependence, in Robins LH, Regier DA (eds): Psychiatric Disorders in America. New York, The Free Press, 1991, pp 81-115

40. Zucker RA, Ellis DA, Bingham CR, Fitzgerald HE: The development of alcoholic subtypes: Risk variation among alcoholic families during the early childhood years. Alcohol Health Res World 20:46-54, 1996

41. Fitzgerald HE, Zucker RA, Yang H-Y: Developmental systems theory and alcoholism: Analyzing patterns of variation in high-risk families. Psychol Addict Behav 9:1-15, 1995 
42. Zucker RA: The four alcoholisms: A developmental account of the etiologic process, in Rivers PC (ed): Nebraska Symposium on Motivation: Alcohol and Addictive Behaviors, vol 34. Lincoln, NE, University of Nebraska Press, 1987, pp 27-83

43. Zucker RA, Ellis DA, Fitzgerald HE, Bingham CR, Sanford DP: Other evidence for at least two alcoholism: II. Life course variation in antisociality and heterogeneity of alcoholic outcome. Develop Psychopathol 8:831-848, 1997

44. Fitzgerald HE, Sullivan LA, Ham HP, et al: Predictors of behavior problems in three-year-old sons of alcoholics: Early evidence for the onset of risk. Child Dev 64:110 -123, 1993

45. Feighner J, Robins E, Guze S, et al: Diagnostic criteria for use in psychiatric research. Arch Gen Psychiatry 26:57-63, 1972

46. Achenbach TM: Manual for the Child Behavior Checklist/4-18 and 1991 profile. Burlington, VT, University of Vermont Department of Psychiatry, 1991

47. Conners CK: Manual for Conners' Rating Scales. Toronto, MultiHealth Systems, Inc., 1990

48. Zucker RA, Noll RB: The Antisocial Behavior Checklist, Department of Psychology. East Lansing, MI, Michigan State University, 1980

49. Zucker RA, Noll RB, Ham H, Fitzgerald HE, Sullivan LS: Assessing Antisociality with the Antisocial Behavior Checklist: Reliability and Validity Studies. East Lansing, MI, Michigan State University, 1992

50. Ichiyama M, Zucker RA, Fitzgerald HE, Bingham CR: Articulating subtype differences in self and relational experience among alcoholic men via structural analysis of social behavior. J Consult Clin Psychol 64:12451254,1996

51. Stevens G, Featherman DL: A revised socioeconomic index of occupational status. Social Sci Res 10:364-395, 1981

52. Anderson GM, Young JG, Cohen DJ, Schlicht KR: Liquid chromatographic determination of serotonin and tryptophan in whole blood and plasma. Clin Chem 27:775-776, 1981

53. Ritvo ER, Yuwiler A, Geller E, et al: Maturational changes in blood serotonin leveis and platelet counts. Biochem Med 5:90-96, 1971

54. Anderson GM, Teff KL, Young SN: Effect of a meal on human whole blood serotonin. Gastroenterology 88:86-89, 1984

55. Badcock NR, Spence JG, Stern LM: Blood serotonin levels in adults, autistic and nonautistic children with a comparison of different methodologies. Ann Clin Biochem 24:625-634, 1987

56. Yuwiler A, Brammer GL, Morley JE, et al: Short-term and repetitive administration of oral tryptophan in normal men. Arch Gen Psychiatry 38:619-626, 1981

57. Cook EH, Anderson GM, Heninger G, et al: Tryptophan loading in hyperserotonemic and normoserotonemic adults. Biol Psychiatry 31:525528,1981

58. Kremer HPH, Goekoop JG, Van Kempen GMJ: Clinical use of the determination of serotonin in whole blood. J Clin Psychopharmacol 10: 83-87, 1990

59. Brewerton RD, Flament MR, Rapoport JL, Murphy DL: Seasonal effects on platelet 5-HT content in patients with OCD and controls. Arch Gen Psychiatry 50:409, 1993

60. Zucker RA, Davies WH, Kincaid SB, Fitzgerald HE, Reider EE: Conceptualizing and scaling the developmental structure of behavior disorder: The lifetime alcohol problems score as an example. Dev Psychopathol 9:1-19, 1997

61. Cook E, Arora R, Anderson G, et al: Platelet serotonin studies in hyperserotonemic relatives of children with autistic disorder. Life Sci 52:2005-2015, 1993

62. Raleigh MJ, Brammer GL, McGuire MT, Pollack DB, Yuwiler A: Individual differences in basal cisternal cerebrospinal fluid 5-HIAA and HVA in monkeys: The effects of gender, age, physical characteristics, and matrilineal influences. Neuropsychopharmacology 7:295-304, 1992

63. Riddle MA, Anderson GM, McIntosh S, et al: Cerebrospinal fluid monoamine precursor and metabolite levels in children treated for leukemia: Age and sex effects and individual variability. Biol Psychiatry $21: 69-83,1986$

64. Higley JD, Suomi SJ, Linnoila M: A nonhuman primate model of type II excessive alcohol consumption: Part 1. Low cerebrospinal fluid 5-hydroxyindoleacetic acid concentration and diminished social competence correlated with excessive alcohol consumption. Alcohol Clin Exp Res 20:629-642, 1996

65. Cloninger CR: Neurogenetic adaptive mechanisms in alcoholism. Science 236:410-416, 1987 